\title{
Benchmarking clinical management of spinal and non-spinal disorders using quality of life: results from the EPI3-LASER survey in primary care
}

\author{
Michel Rossignol • Bernard Begaud • Bernard Avouac France Lert $\cdot$ Frederic Rouillon • \\ Jacques Bénichou · Jacques Massol • Gerard Duru • Anne-Marie Magnier • \\ Didier Guillemot • Lamiae Grimaldi-Bensouda • Lucien Abenhaim
}

Received: 19 September 2010/Revised: 13 January 2011/Accepted: 25 March 2011/Published online: 13 April 2011

(C) The Author(s) 2011. This article is published with open access at Springerlink.com

\begin{abstract}
Concerns have been raised regarding sub-optimal utilization of analgesics and psychotropic drugs in the treatment of patients with chronic musculoskeletal disorders (MSDs) and their associated co-morbidities. The objective of this study was to describe drug prescriptions for the management of spinal and non-spinal MSDs contrasted against a standardized measure of quality of life. A representative population sample of 1,756 MSDs patients $[38.5 \%$ with spinal disorder (SD) and $61.5 \%$ with non-
\end{abstract}

\author{
M. Rossignol ( $\square)$ \\ Department of Epidemiology, Biostatistics and Occupational \\ Health, McGill University, 4820 Boulevard Saint-Laurent, \\ Montreal, QC H2T 1R5, Canada \\ e-mail: Michel.Rossignol@CRR-Intl.com \\ M. Rossignol \\ LA-SER Centre for Risk Research, 4820 Boulevard \\ Saint-Laurent, Montreal, QC H2T 1R5, Canada \\ B. Begaud \\ Université de Bordeaux, U657, 33000 Bordeaux, France \\ e-mail: Bernard.Begaud@pharmaco.u-bordeaux2.fr \\ B. Avouac · L. Grimaldi-Bensouda \\ LA-SER, Paris, France \\ e-mail: Bavouac@la-ser.com \\ L. Grimaldi-Bensouda \\ e-mail: Lamiae.Grimaldi@pgrx.net \\ F. Lert \\ INSERM U1018, Center for Epidemiology and Population \\ Health, Villejuif, France \\ e-mail: France.Lert@inserm.fr \\ F. Rouillon \\ Centre Hospitalier Sainte-Anne, \\ Université Paris V René Descartes, Paris, France \\ e-mail: F.Rouillon@ch-sainte-anne.fr
}

spinal MSDs (NS-MSD)] was drawn from the EPI3LASER survey of 825 general practitioners (GPs) in France. Physicians recorded their diagnoses and prescriptions on that day. Patients provided information on sociodemographics, lifestyle and quality of life using the Short Form 12 (SF-12) questionnaire. Chronicity of MSDs was defined as more than 12 weeks duration of the current episode. Chronic SD and NS-MSD patients were prescribed less analgesics and non-steroidal anti-inflammatory

\author{
J. Bénichou \\ INSERM U657, University of Rouen, Rouen, France \\ e-mail: Jacques.Benichou@chu-rouen.fr \\ J. Bénichou \\ Department of Biostatistics, University Hospital of Rouen, \\ Rouen, France \\ J. Massol \\ Université Franche-Comté, CHU de Besançon, \\ Besançon, France \\ e-mail: Jacques.Massol@univ-fcomte.fr \\ G. Duru \\ CNRS (French National Center for Scientific Research), \\ Université Claude Bernard, Lyon, France \\ e-mail: Gerard.Duru@gmail.com
A.-M. Magnier France
e-mail: AMMagnier@nerim.fr
D. Guillemot
Institut Pasteur and Université Paris-Ile de France Ouest,
Paris, France
e-mail: Didier.Guillemot@Pasteur.fr \\ Faculté de Médecine Université Pierre et Marie Curie, Paris,
}


drugs than their non-chronic counterpart [odds ratios (OR) and $95 \%$ confidence intervals (CI), respectively: 0.4 , $0.2-0.7$ and $0.5,0.3-0.6]$. They also had more anxiodepressive co-morbidities reported by their physicians (SD: 16.1 vs. $7.4 \%$; NS-MSD: 21.6 vs. $9.5 \%$ ) who prescribed more antidepressants and anxiolytics with a difference that was statistically significant only for spinal disorder patients (OR, 95\% CI: 2.0, 1.1-3.6). Psychotropic drugs were more often prescribed in patients in the lower quartile of SF-12 mental score and prescriptions of analgesics in the lower quartile of SF-12 physical score $(P<0.001)$. In conclusion, anxiety and depressive disorders were commonly reported by GPs among chronic MSD patients. Their prescriptions of psychotropic and analgesic drugs were consistent with patients' self-rated mental and physical health.

Keywords Spinal disorders - Musculoskeletal disorders . Epidemiology $\cdot$ Population health

\section{Introduction}

Physicians in primary care play a central role in the management of musculoskeletal disorders (MSDs). In France, as in most industrialized countries, they represent one of the most frequent reasons for consultation [1]. Clinical guidelines emphasize the treatment of pain and inflammation in the acute phase with gradual recourse to stronger analgesia and the management of psychological impacts as the condition evolves toward chronicity. In this context, concerns have been raised regarding sub-optimal use of analgesics and psychotropic drugs (antidepressants) in the treatment of patients with chronic MSDs [2, 3]. This issue has been examined by comparing guidelines with actual practice in benchmarking approaches $[4,5]$. The goal of this study was to describe physician's prescriptions for the management of acute and chronic MSDs in a large population of patients seen in primary care, and examine the pertinence of prescriptions against patient's self-assessed quality of life.

L. Grimaldi-Bensouda

Equipe d'accueil 'Pharmacoépidémiologie et maladies infectieuses', Institut Pasteur,

Paris, France

L. Abenhaim

LA-SER Europe Ltd, London, UK

e-mail: Lucien.Abenhaim@gmail.com

L. Abenhaim

Department of Epidemiology, London School of Hygiene and

Tropical Medicine, London, UK

\section{Materials and methods}

Study design and population

The EPI3-LASER study was a nation-wide observational survey of a representative sample of general practitioners (GPs) and their patients, conducted in France between March 2007 and July 2008. Its aims were to assess the burden of disease in general practice, considering physician and patients characteristics, co-morbidities and prescriptions with a specific focus on health-related quality of life.

The study population was drawn from a two-stage sampling. First, GPs were randomly selected from the French national directory of physicians and invited to participate, which meant allowing a research assistant to be in the patients' waiting room for a 1-day consultation session, collecting basic information on all patients consulting that day and recruiting volunteers to fill out a selfadministered questionnaire. The second stage consisted of randomly sampling the 1-day of consultation for each participating physician to survey all patients attending the practice on that specific day. GPs sampling was stratified to take into account the diversity of practices (strict conventional medicine and use of homeopathy and other complementary medicines).

All patients were eligible for inclusion to the exception of those whose health status or literacy level did not allow responding to a self-administered questionnaire. On the day selected for patients inclusion, a trained interviewer recruited on site, in the waiting room, all consecutive eligible patients up to a maximum of 15 . Consenting patients completed a self-administered questionnaire that included information on age, gender, education, employment status and occupation, type of health insurance, hospitalization and medical visits in the previous 12 months, smoking, alcohol intake, physical activity, height and weight, and health related quality of life assessed by the Short Form 12 (SF-12) questionnaire [6-8].

GPs completed a medical questionnaire including the main reason for consultation and up to five other diagnoses present that day and for each, the duration of the health problem in its current episode. No diagnostic criteria was provided in this survey. GPs reported their diagnoses as they normally do it in their usual practice. GPs also recorded their prescriptions that day for diagnostic tests, drugs and referrals. Diagnoses were coded by a trained archivist using the 9th revision of the International Classification of Diseases. In this analysis adult patients 18 years and older with a MSD as their main reason for consultation were included. MSDs were classified as spinal disorders (SD) with ICD codes 720-724, and non-spinal MSDs (NS-MSD), such as osteoarthritis and tendonitis of the upper or lower limb, with ICD codes $715,719,729$, 
726-728, 782. Patients with a diagnosis of inflammatory, infectious or neoplastic joint disease as their main reason for consultation were excluded from the analyses. SD and NS-MSD were classified as acute-subacute or chronic using a 12-week (3 months) cut-off for duration of symptoms in the current episode in accordance with consensus recommendations for research on SD [9]. Patients, interviewers and physicians were blind to the specific objectives of this analysis.

\section{Statistical analysis}

Characteristics of non-participating patients (gender, age, length of time attending the GPs' practice, type of health insurance and main reason for consultation) were used to calibrate the final sample so that it represented more closely the whole study population, using a procedure known in demographic studies as the CALMAR procedure [10]. Factors associated with chronicity were identified in multiple logistic regression analyses. Odds ratios were calculated for the comparison of prescriptions between chronic and non-chronic patients using mixed models accounting for a random physician effect (GLIMMIX and NLMIXED procedures in SAS). Mean scores of the SF-12 mental and physical scales were adjusted for gender, age and comorbidities using the analysis of covariance. Tests for trend on proportions of medication users by quartile of the SF-12 subscales were performed using the Cochrane-Armitage test for trend. All analyses were performed using SAS version 9.1 .

The study was approved by the French National DataProtection Commission (CNIL) and the French National Council of Physicians (CNOM). Participating physicians received compensation fees but not patients.

\section{Results}

Of the 17,206 GPs randomly selected and invited by mail to participate, 825 agreed to participate in the study. Their geographical distribution covered the 22 regions of France. Their median age was 52 years, $23.5 \%$ were female, $51.8 \%$ worked in solo practice and $7.6 \%$ practiced fee-for-service in addition to the general health insurance regime. The median number of patients recruited at each physicians' office was two with $11.2 \%$ recruiting five or more. Of the 10,803 patients identified as potential participants, 2,151 (19.9\%) declined participation and 93 were excluded because of missing information leaving a final sample of 8,559 , of whom $665(7.8 \%)$ had a SD as their main reason for consultation, and 1,027 (12.0\%) a NS-MSD (Table 1). They were female in proportions of 59.0 and $61.6 \%$ for SD and NS-MSD, respectively, and SD patients were younger by 8.2 years on average. The proportion who had their problem for 12 weeks or more at the time of consultation were respectively 43.0 and $58.5 \%$ for SD and NS-MSD. Factors associated with chronicity of SD were age, with the largest proportion observed over the age of 60 [odds ratio (OR): 4.5, 95\% confidence interval (CI): 2.1-9.6], and not being employed (OR $=2.0,95 \%: 1.1-3.6)$. For NS-MSD, factors associated with chronicity were female gender $(\mathrm{OR}=1.7,95 \%$ CI: $1.2-2.3)$ and age (OR for patients 60 and over $=2.3,95 \%$ CI: 1.2-4.4). Physician's characteristics (sex, age and fee-for-service practice) were not associated with chronicity.

Physicians declared about twice as much MSD comorbidities (at least one secondary MSD diagnosis) for their chronic patients than their acute-subacute patients (Table 2). After controlling for age and gender, the odds ratio of having a MSD co-morbidity in chronic SD patients was 2.4 (95\% CI: 1.5-4.0) and in chronic NS-MSD patients, 1.7 (95\% CI: 1.1-2.7). Chronic patients also had about twice as much anxiety, depressive and sleeping disorders diagnoses than their acute-subacute counterpart with odds ratios respectively in SD and NS-MSD patients of 1.9 (95\% CI: $1.2-2.9)$ and 2.0 (95\% CI: 1.5-2.8). Differences between acute-subacute and chronic patients for digestive co-morbidities were not statistically significant but an excess cardiovascular disorders was observed in chronic NS-MSD patients (OR $=1.5,95 \%$ CI: 1.1-1.9) which was essentially explained by a four times higher number of hypertensive patients compared to their acutesubacute counterpart (16 against 4).

Quality of life scores (SF12) were almost identical between SD and NS-MSD patients. Chronic SD patients had a physical mean score adjusted for age, gender and comorbidities, 2.4 points lower than acute-subacute patients $(P=0.001)$, while their mental scores were almost identical. The reverse was observed in NS-MSD patients where the difference was observed in the mental scale with a difference of 1.7 points lower among chronic patients $(P=0.004)$.

Chronic SD and NS-MSD patients received half the analgesics, non-steroidal anti-inflammatory drugs (NSAIDs) and muscle relaxants prescriptions than their acutesubacute counterpart after controlling for co-morbidities and other confounding factors [Table 3, OR $=0.4(95 \%$ CI: $0.2-0.7)$ and 0.5 (95\% CI: 0.3-0.6), respectively, statistically significant]. The reverse was observed for antidepressants, anxiolytics and hypnotics with almost twice more prescriptions in chronic SD patients $(\mathrm{OR}=2.0,95 \%$ CI: $1.1-3.6)$ but not in NS-MSD patients (OR $=1.3,95 \%$ CI: 0.8-2.1). For non-pharmacological prescriptions, imaging was almost twice as much prescribed in acutesubacute than chronic patients but there was no statistical difference with referral to physiotherapy or to a specialist. 
Table 1 Socio-demographic characteristics of patients with musculoskeletal disorders (MSD) in primary care $(N=1,692)$

\begin{tabular}{|c|c|c|c|c|c|c|}
\hline & \multicolumn{3}{|c|}{ Spinal disorders } & \multicolumn{3}{|c|}{ Non-spinal MSD (upper and lower limb) } \\
\hline & $\begin{array}{l}\text { Total } \\
N=665\end{array}$ & $\begin{array}{l}\leq 12 \text { weeks } \\
N=376\end{array}$ & $\begin{array}{l}>12 \text { weeks } \\
N=289\end{array}$ & $\begin{array}{l}\text { Total } \\
N=1027\end{array}$ & $\begin{array}{l}\leq 12 \text { weeks } \\
N=404\end{array}$ & $\begin{array}{l}>12 \text { weeks } \\
N=623\end{array}$ \\
\hline Gender of patients ( $\%$ Female $)$ & 59.0 & 57.1 & 62.1 & 61.6 & $51.9 *$ & $69.2 *$ \\
\hline Age of patients (mean, SD) & $49.6(14.1)$ & $47.0 *(14.3)$ & $53.7 *(13.2)$ & $57.9(15.2)$ & $53.3 *(16.6)$ & $61.5^{*}(13.2)$ \\
\hline \multicolumn{7}{|l|}{ Employment status (\%) } \\
\hline Employed & 58.4 & $64.8 *$ & $48.2 *$ & 38.6 & 46.8 & 32.2 \\
\hline On unemployment benefits & 3.0 & 3.0 & 2.8 & 2.9 & 2.6 & 3.1 \\
\hline Home maker & 3.2 & 2.2 & 5.0 & 3.5 & 2.7 & 4.0 \\
\hline Student & 2.5 & 3.1 & 1.6 & 2.0 & 3.5 & 0.9 \\
\hline Retired, other unemployed & 31.3 & 25.2 & 40.8 & 52.3 & 43.5 & 59.2 \\
\hline Education (\% completed high school) & 43.3 & 48.9 & 33.9 & 35.2 & 44.9 & 27.6 \\
\hline \multicolumn{7}{|l|}{ Familial status $(\%)$} \\
\hline Living with a spouse & 69.3 & 69.8 & 68.6 & 64.9 & 66.6 & 63.4 \\
\hline Living with children & 44.3 & 45.3 & 43.0 & 30.7 & 32.7 & 29.2 \\
\hline \multicolumn{7}{|l|}{ Body mass index (\%) } \\
\hline $0-24$ & 49.1 & 51.2 & 45.9 & 45.1 & 48.9 & 42.1 \\
\hline $25-29$ & 37.3 & 35.4 & 40.4 & 34.3 & 33.9 & 34.6 \\
\hline 30 and over & 11.9 & 11.6 & 12.3 & 19.7 & 17.1 & 21.8 \\
\hline \multicolumn{7}{|l|}{ Tobacco consumption (\%) } \\
\hline Never smoked & 44.8 & 44.6 & 44.8 & 53.0 & 49.8 & 55.5 \\
\hline Past smoker & 25.4 & 23.7 & 28.1 & 25.5 & 25.2 & 25.7 \\
\hline Current smoker & 29.5 & 31.3 & 26.9 & 21.4 & 25.0 & 18.7 \\
\hline \multicolumn{7}{|l|}{ Alcohol consumption (\%) } \\
\hline Never & 33.9 & 30.5 & 39.8 & 32.3 & 31.5 & 32.8 \\
\hline Sometimes & 56.3 & 57.9 & 53.7 & 49.7 & 50.4 & 49.2 \\
\hline Daily & 9.3 & 10.9 & 6.4 & 17.9 & 18.1 & 17.7 \\
\hline \multicolumn{7}{|l|}{ Physical exercise (\%) } \\
\hline $0-30$ min per day & 59.2 & 61.1 & 56.0 & 58.8 & 54.6 & 62.1 \\
\hline $31 \mathrm{~min}$ and over & 38.3 & 35.9 & 42.3 & 39.6 & 44.2 & 36.0 \\
\hline \multicolumn{7}{|l|}{ Physician visit previous 12 months } \\
\hline Yes & 96.0 & 95.3 & 97.1 & 96.4 & 95.0 & 97.5 \\
\hline
\end{tabular}

* Comparison $\leq 12$ weeks, $>12$ weeks statistically significant $(P<0.05)$ in multiple logistic regression including all variables in the table

Frequencies of prescription of analgesics and of psychotropic drugs (antidepressant, anxiolytic and hypnotic drugs combined) in all chronic patients (SD and NSMSD), were computed by SF-12 mental and physical scores (Table 4). Two statistically significant trends were found, one for psychotropic drugs increasing with a decreasing (worsening) mental score, and the other for analgesic drugs increasing with decreasing (worsening) physical score. Similar trends were observed with physicians reporting of MSD and anxio-depressive co-morbidities but reached statistical significance only in the former. It is noteworthy that among chronic patients in the lower decile of SF-12 mental score (not shown in Table 4), $42.2 \%$ (38/91) were prescribed a psychotropic drug.

\section{Discussion}

Physicians' participation to this survey was low in part due to the important intrusive nature of the study into their practice. We found no equivalent in the scientific literature for a study of this size and the large population of patients was nevertheless representative of the French population consulting a GP. First, the distribution of GPs individual characteristics differed from published national statistics only for gender with $23.5 \%$ female in the Epi3 survey versus 39\% in all of France for the year 2008 [11]. This difference had potentially little impact on patients' results as physicians' characteristics were not associated with chronicity in our analyses. In addition, patients' non participation was partially controlled by a weighting 
Table 2 Co-morbidities and quality of life in patients with musculoskeletal disorders (MSD) in primary care $(N=1,692)$

\begin{tabular}{|c|c|c|c|c|c|c|}
\hline \multirow[t]{2}{*}{ Co-morbidities present at the medical visit } & \multicolumn{3}{|c|}{ Spinal disorders } & \multicolumn{3}{|c|}{ Non-spinal MSD (upper and lower limb) } \\
\hline & $\begin{array}{l}\text { Total } \\
N=665\end{array}$ & $\begin{array}{l}\leq 12 \text { weeks } \\
N=376\end{array}$ & $\begin{array}{l}>12 \text { weeks } \\
N=289\end{array}$ & $\begin{array}{l}\text { Total } \\
N=1027\end{array}$ & $\begin{array}{l}\leq 12 \text { weeks } \\
N=404\end{array}$ & $\begin{array}{l}>12 \text { weeks } \\
N=623\end{array}$ \\
\hline MSD co-morbidities (\%) & 11.6 & $8.3^{*}$ & $16.9 *$ & 7.6 & $5.8^{*}$ & $8.9^{*}$ \\
\hline \multicolumn{7}{|l|}{ Other co-morbidities $(\%)^{\mathrm{a}}$} \\
\hline At least one & 32.3 & $26.8 *$ & $41.1 *$ & 56.1 & $40.9 *$ & $68.0 *$ \\
\hline Anxio-depressive disorders & 10.7 & $7.4^{*}$ & $16.1 *$ & 16.3 & $9.5^{*}$ & $21.6^{*}$ \\
\hline Sleeping disorders & 2.7 & $1.3 *$ & $5.0^{*}$ & 5.1 & $3.7 *$ & $6.2^{*}$ \\
\hline Cardiovascular-respiratory & 19.3 & 18.0 & 21.1 & 37.2 & $25.4^{*}$ & $46.4 *$ \\
\hline Digestive disorders & 6.1 & 7.0 & 4.4 & 8.8 & 5.8 & 11.1 \\
\hline \multicolumn{7}{|l|}{ Quality of life SF-12 } \\
\hline Mental score mean (SD) & $39.9(1.2)$ & $40.8(2.0)$ & $40.5(2.0)$ & $40.6(1.1)$ & $41.5^{*}(1.6)$ & $39.8 *(1.4)$ \\
\hline Physical score mean (SD) & $42.2(1.3)$ & $42.0 *(2.2)$ & $39.6^{*}(2.2)$ & $42.7(1.2)$ & $44.0(1.6)$ & $43.1(1.4)$ \\
\hline
\end{tabular}

* Comparison $\leq 12$ and $>12$ weeks: $P<0.01$

${ }^{a}$ ICD-9 codes for anxio-depressive disorders: 300-316, 799; sleeping disorders: 780; cardiovascular: 415-426, 428-448, 785; respiratory: 472-474, 476-477, 490-496; digestive: 520-537, 540-553, 555-558, 560-579, 787, 789

b Mean adjusted for age, gender and presence of co-morbidities

Table 3 Prescriptions at the medical visit in patients with musculoskeletal disorders (MSD) in primary care $(\mathrm{N}=1,692)$

\begin{tabular}{|c|c|c|c|c|c|c|}
\hline & \multicolumn{3}{|c|}{ Spinal disorders } & \multicolumn{3}{|c|}{ Non-spinal MSD (upper and lower limb) } \\
\hline & $\begin{array}{l}\text { Total } \\
N=665\end{array}$ & $\begin{array}{l}\leq 12 \text { weeks } \\
N=376\end{array}$ & $\begin{array}{l}>12 \text { weeks } \\
N=289\end{array}$ & $\begin{array}{l}\text { Total } \\
N=1027\end{array}$ & $\begin{array}{l}\leq 12 \text { weeks } \\
N=404\end{array}$ & $\begin{array}{l}>12 \text { weeks } \\
N=623\end{array}$ \\
\hline \multicolumn{7}{|l|}{ At least one (\%) } \\
\hline Analgesics & 56.8 & 61.5 & 49.1 & 45.3 & 50.5 & 41.4 \\
\hline NSAID (without aspirin) & 40.9 & 45.7 & 33.5 & 30.2 & 41.4 & 21.4 \\
\hline Muscle relaxants & 31.1 & 38.0 & 20.0 & 5.8 & 7.1 & 4.8 \\
\hline Anti-osteoarthritis drugs & 0.4 & 0.2 & 0.6 & 5.8 & 1.9 & 8.9 \\
\hline$>12$ versus $\leq 12$ weeks OR $(95 \% \mathrm{CI}) *$ & & $1.0(-)$ & $0.4(0.2-0.7)$ & & $1.0(-)$ & $0.5(0.3-0.6)$ \\
\hline \multicolumn{7}{|l|}{ At least one (\%) } \\
\hline Antidepressants & 7.5 & 4.6 & 12.1 & 8.9 & 4.3 & 12.5 \\
\hline Anxiolytics & 5.0 & 3.9 & 6.9 & 9.0 & 5.8 & 11.6 \\
\hline Hypnotics & 3.4 & 1.7 & 6.1 & 6.6 & 4.5 & 8.3 \\
\hline$\geq 12$ versus $\leq 12$ weeks OR $(95 \% \mathrm{CI}) *$ & & $1.0(-)$ & $2.0(1.1-3.6)$ & & $1.0(-)$ & $1.3(0.8-2.1)$ \\
\hline \multicolumn{7}{|l|}{ A least one $(\%)$} \\
\hline Imaging (X-rays, CT scan or MRI) & 16.2 & 19.9 & 10.3 & 14.2 & 18.5 & 10.9 \\
\hline Lab tests & 11.2 & 12.0 & 9.9 & 13.2 & 10.9 & 15.0 \\
\hline$>12$ versus $\leq 12$ weeks OR $(95 \% \mathrm{CI}) *$ & & $1.0(-)$ & $0.4(0.3-0.8)$ & & $1.0(-)$ & $0.7(0.5-1.0)$ \\
\hline \multicolumn{7}{|l|}{ A least one $(\%)$} \\
\hline Physiotherapy & 17.6 & 17.8 & 17.3 & 13.6 & 13.4 & 13.8 \\
\hline Reference to a specialist & 9.1 & 6.6 & 13.2 & 17.6 & 15.1 & 19.7 \\
\hline$>12$ versus $\leq 12$ weeks OR $(95 \% \mathrm{CI})^{*}$ & & $1.0(-)$ & $0.9(0.6-1.4)$ & & $1.0(-)$ & $1.0(0.7-1.4)$ \\
\hline
\end{tabular}

* Odds ratios and 95\% confidence intervals derived from multivariate mixed regression models adjusting for all variables in Tables 1 and 2 and for physician's effect

procedure based on socio-demographic information collected on non-respondents at recruitment. Secondly, SF-12 scores observed in our study were not far away from those reported in three European population surveys of patients with MSDs, and score differences between acute and chronic patients were also similar [12, 13]. Finally, 
Table 4 Analgesic and psychotropic drugs prescription in patients with MSDs of more than 12 weeks duration by quality of life quartiles $(N=911)$

\begin{tabular}{cc|cccc} 
& \multicolumn{5}{|c}{ SF-12 Mental score (Quartiles) } \\
At least one (\%) & Total & Q1 & Q2 & Q3 & Q4 \\
& & & & & \\
Analgesics prescription & 43.5 & 45.7 & 46.2 & 34.2 & 48.0 \\
MSD co-morbidity & 5.1 & 3.8 & 5.2 & 6.3 & 5.2 \\
\hline Psychotropic ${ }^{1}$ prescription & 22.3 & $36.8^{*}$ & $23.8^{*}$ & $8.9^{*}$ & $17.5^{*}$ \\
Anxio-depressive co-morbidity & 25.9 & $44.4^{*}$ & $27.5^{*}$ & $14.4^{*}$ & $13.7^{*}$ \\
& \multicolumn{5}{|c|}{ SF-12 Physical score (Quartiles) } \\
Analgesics prescription & 43.5 & $49.9^{*}$ & $44.4^{*}$ & $47.4^{*}$ & $31.2^{*}$ \\
MSD co-morbidity & 5.1 & 7.1 & 4.5 & 5.8 & 2.9 \\
\hline Psychotropics ${ }^{1}$ prescription & 22.3 & 23.4 & 23.0 & 17.4 & 26.2 \\
Anxio-depressive co-morbidity & 25.9 & 28.9 & 23.0 & 25.5 & 26.1
\end{tabular}

* Test for trend: $P<0.001$

a Antidepressants, anxiolytics and hypnotics

NSAIDs utilization was close to what has been observed in two other studies but our frequency of prescription of antidepressants was about half [2-14]. Prescription of physiotherapy was also lower than what has been reported in another French survey [15]. Differences could be attributed to the cross-sectional nature of the surveys, differences in sources of information and type of insurance coverage of the patients.

The impact of chronicity on quality of life, co-morbidities and prescriptions was similar between SD and NSMSD patients. Our study showed that drug prescription in primary care was well correlated to physical and mental patient's self-assessed quality of life, using a standardized instrument independent from the clinician's evaluation. The neat gradient of prescription of psychotropic drugs with the mental scale and of analgesics with the physical scale of the SF-12, provided evidence of the pertinence of physician's prescriptions. For instance, chronic MSD patients were twice as likely to have anxio-depressive and sleeping disorders, a burden that has been raised in systematic reviews [16, 17]. The concomitant presence of chronic pain and anxio-depressive disorders has been at the source of confusion in the scientific literature on efficacy of antidepressants against chronic pain [18, 19]. Our results indicated that clinicians seemed able to adapt their prescription to the pain and psychological components for their chronic pain patients.

Our results showed that over $50 \%$ of chronic patients with a very low mental score (lower decile) received no prescription for a psychotropic drug. This is not in contradiction, however, with recent evidence that indicates limited or no benefit of antidepressant drugs in populations with mild or moderate symptoms, which would account for a significant proportion of chronic pain patients [20].

The prevalence of sleeping problems was low compared to what has been reported in a systematic review on that topic but data remains sparse on this topic [16]. Sleeping disorders have been associated to pain intensity but not to duration (chronicity) of symptoms which is the marker usually cited in clinical guidelines. Anxio-depressive symptoms and sleeping quality should be a systematic part of the medical questionnaire with chronic MSD patients because of their impact on quality of life.

The high hypertension and digestive disorders observed in patients consulting for MSDs in primary care has been reported in another study and was partly explained by age [13]. The higher, but not statistically significant, digestive co-morbidities observed in chronic compared to acutesubacute NS-MSD patients might explain the lower prescription of NSAIDs in that group [21].

The main limitation of this study was the cross-sectional nature of data collection and analyses. Associations found between quality of life and prescriptions for instance, cannot be interpreted as causally linked. Prescriptions of the day was a mix of new prescriptions and renewals and represented the patients' status at one point in time. Because patients responded to the SF-12 questionnaire before they saw their physician in consultation, there is a possibility that this had influenced physicians' diagnoses and prescriptions. Two elements contributed to minimize this effect if it existed. First, the scoring procedure used to derive mental and physical scores from responses to the SF-12 questionnaire, was not known from patients. Secondly, the SF-12 questionnaire was included in a general questionnaire on health that did not focus on any specific health issue.

Another limitation was the declarative nature of diagnoses and prescriptions provided by participating physicians. No diagnostic criteria was suggested for reporting MSDs diagnoses ore anxio-depressive co-morbidities. This was a deliberate choice in order to describe clinical practice in real life situation. We feel confident that the large number of participating physicians and patients contributed to the overall representativity of clinical practice in primary care in France. In addition, MSD patients were identified from a large sample of patients consulting for any reason in primary care, thus minimizing biases related to sampling MSD patients directly. The main strength of the study was the combination of medical information on diagnoses and prescriptions on one hand, and patients' information on quality of life on the other hand, both collected on the day of consultation insuring timely compatibility. 


\section{Conclusion}

In conclusion, important differences were observed in the clinical management of acute-subacute and chronic MSD French patients in primary care. Anxiety and depressive disorders were commonly reported by GPs among chronic MSD patients. GPs' prescriptions of psychotropic and analgesic drugs seemed pertinent as they were consistent with a standardized measure of quality of life, independent from the clinicians' judgement. This utilization of patients' self-assessed quality of life provided a useful benchmarking approach to assess consistency between clinical practice and guidelines.

Acknowledgments Laboratoires Boiron, France sponsored the study which was independently run and published by the authors. Lamiae Bensouda-Grimaldi was the recipient of a research fellowship from INSERM (French National Institute of Health and Medical Research). The authors wish to thank Ms. Djamila Abed and Rémi Sitta for their technical assistance with statistical analyses. Members of the LA-SER network have no interest in a drug or other factors studied. The study was approved by the French National Data-Protection Commission (CNIL) and the French National Council of Physicians (CNOM). Participating physicians received compensation fees but not patients.

Open Access This article is distributed under the terms of the Creative Commons Attribution Noncommercial License which permits any noncommercial use, distribution, and reproduction in any medium, provided the original author(s) and source are credited.

\section{References}

1. Rossignol M, Rozenberg S, Leclerc A (2009) Epidemiology of low back pain: what's new? Jt Bone Spine 76:608-613

2. Carey TS, Freburger JK, Holmes GM et al (2009) A long way to go: practice patterns and evidence in chronic low back pain care. Spine 34:718-724

3. Lefevre-Colau MM, Fayad F, Rannou F et al (2009) Frequency and interrelations of risk factors for chronic low back pain in a primary care setting. PLoS One 4:e4874

4. Arnau JM, Vallano A, Lopez A et al (2006) A critical review of guidelines for low back pain treatment. Eur Spine J 15:543-553

5. Poitras S, Avouac J, Rossignol M et al (2007) A critical appraisal of guidelines for the management of knee osteoarthritis using Appraisal of Guidelines Research and Evaluation criteria. Arthritis Res Ther 9:R126

6. Gandek B, Ware JE, Aaronson NK et al (1998) Cross-validation of item selection and scoring for the SF-12 Health Survey in nine countries: results from the IQOLA Project. International Quality of Life Assessment. J Clin Epidemiol 51:1171-1178

7. Resnick B, Nahm ES (2001) Reliability and validity testing of the revised 12-item Short-Form Health Survey in older adults. J Nurs Meas 9:151-161

8. Ware J Jr, Kosinski M, Keller SD (1996) A 12-Item Short-Form Health Survey: construction of scales and preliminary tests of reliability and validity. Med Care 34:220-233

9. Dionne CE, Dunn KM, Croft PR et al (2008) A consensus approach toward the standardization of back pain definitions for use in prevalence studies. Spine 33:95-103

10. Deville J-C, Särndal C-E (1992) Calibration estimation in survey sampling. J Am Stat Assoc 87:375-382

11. Institut de recherche et documentation en économie de la santé (2008) Démographie des médecins. IRDES, Paris, France. http://www.irdes.fr. Accessed 2 February 2010

12. Kadam UT, Schellevis FG, Lewis M et al (2009) Does age modify the relationship between morbidity severity and physical health in English and Dutch family practice populations? Qual Life Res 18:209-220

13. Loza E, Jover JA, Rodriguez L, the EPISER Study Group (2009) Multimorbidity: prevalence, effect on quality of life and daily functioning, and variation of this effect when one condition is a rheumatic disease. Semin Arthritis Rheum 38:312-319

14. Licciardone JC (2008) The epidemiology and medical management of low back pain during ambulatory medical care visits in the United States. Osteopath Med Prim Care 2:11

15. Depont F, Hunsche E, Abouelfath A et al (2010) Medical and non-medical direct costs of chronic low back pain in patients consulting primary care physicians in France. Fundam Clin Pharmacol 24:101-108

16. Collins L (2009) Sleep problems are common and sleep quality is poor in non-specific low back pain: a systematic review of the literature. Xth International Forum on the Study of Low-Back Pain in Primary Care, Boston, MA. http//www.lbpforum.org. Accessed 2 February 2010

17. Pincus T, Vogel S, Burton AK et al (2006) Fear avoidance and prognosis in back pain: a systematic review and synthesis of current evidence. Arthritis Rheum 54:3999-4010

18. Kroenke K, Krebs EE, Bair MJ (2009) Pharmacotherapy of chronic pain: a synthesis of recommendations from systematic reviews. Gen Hosp Psychiatry 31:206-219

19. Urquhart DM, Hoving JL, Assendelft WW et al. (2008) Antidepressants for non-specific low back pain. Cochrane Database Syst Rev (1):CD001703

20. Fournier JC, DeRubeis RJ, Hollon SD et al (2010) Antidepressant drug effects and depression severity: a patient-level meta-analysis. JAMA 303:47-53

21. Depont F, Fourrier A, Merlière Y, the CADEUS Research Group (2007) Channelling of COX-2 inhibitors to patients at higher gastrointestinal risk but not at lower cardiovascular risk: the Cox2 inhibitors and tNSAIDs description of users (CADEUS) study. Pharmacoepidemiol Drug Saf 8:891-900 